Jurnal Geliga Sains 7(1), 40-45, 2019

(c) Program Studi Pendidikan Fisika FKIP Universitas Riau

ISSN 1978-502X; e-ISSN 2614-5383

\title{
DESIGN OF DIGITAL SHOE BASED SHOES SKIN MODELING AND CUTTING MACHINE
}

\author{
Dita Trisna Panjaitan ${ }^{* 1)}$, Jeksen Kristian Sinaga ${ }^{2)}$, Nurul Qodri ${ }^{3)}$, \\ Vianola Elisa Karo Sekali ${ }^{4)}$, Fatuan Arif Sitorus ${ }^{5}$, Rita Juliani $^{6}$ ) \\ ${ }^{1,2)}$ Physics Education, Medan State University \\ ${ }^{3)}$ Automotive Engineering Education, Medan State University \\ ${ }^{4)}$ Fashion Education, Medan State University \\ ${ }^{5)}$ Mechanic Engineering Education, Medan State University \\ ${ }^{6}$ Physics Department, Medan State University \\ e-mail: ditapanjaitan02@gmail.com \\ jeksenkristian3024@gmail.com \\ nqodri@gmail.com \\ vianolaelisa@gmail.com \\ fatuanarif@gmail.com \\ julianiunimed@gmail.com
}

\begin{abstract}
Bunut is one of regions in Kisaran. The majority of Asahan District work as shoe craftsmen. The length time of shoes making procces make the shoe craftsmen need long time to market it. Similarly when designing shoe model that still us traditional tools that make shoe's model impressed outdated. In terms of making Bunut shoe is not easy. Cutting leather shoe that use traditional tools make the cutting process of the shoe becomes long. The method is started from designing a modeling tool, preparing tools and material, making and testing machines. The result obtained by this shoe modeling machine work optimally 8 hours per day with the cutting velocity 1,4 minutes for each shoe's pattern, from the result modelling machine able to cut design pattern a pair of shoes in 40 minutes. So in one day it can produce shoe pattern pieces is able to produce 12 pairs of shoe patterns from the previous one, only 2 pairs per day.
\end{abstract}

Keywords: Bunut shoes, leather shoe cutter, digital modeling mechine.

\section{RANCANG BANGUN MESIN PEMODELING DAN PEMOTONG KULIT SEPATU BERBASIS DIGITAL}

\author{
Dita Trisna Panjaitan $^{* 1)}$, Jeksen Kristian Sinaga ${ }^{2)}$, Nurul Qodri ${ }^{3)}$, \\ Vianola Elisa Karo Sekali ${ }^{4)}$, Fatuan Arif Sitorus ${ }^{5}$, Rita Juliani' \\ ${ }^{1,2)}$ Pendidikan Fisika, Universitas Negeri Medan, \\ ${ }^{3)}$ Pendidikan Teknik Otomotif, Universitas Negeri Medan, \\ 4) Pendidikan Tata Busana Universitas Negeri Medan \\ ${ }^{5)}$ Pendidikan Teknik Mesin, Universitas Negeri Medan \\ ${ }^{6)}$ Fisika, Universitas Negeri Medan
}

*) Komunikasi Penulis 


\begin{abstract}
Abstrak
Bunut merupakan salah satu kecamatan di kota Kisaran yang mayoritasnya bekerja sebagai pengrajin sepatu bunut. Lamanya proses pembuatan sepatu membuat proses produksi menjadi lama sehingga menghambat proses pemasaran. Begitu juga dalam hal desain model sepatu yang masih menggunakan alat tradisional sehingga model sepatu terkesan ketinggalan zaman Dalam hal pembuatan sepatu Bunut tidaklah gampang. Memotong kulit sepatu yang masih menggunakan alat tradisional membuat lamanya proses pemotongan kulit sepatu. Metode yang digunakan dimulai dari merancang alat pemodeling, penyediaan alat dan bahan, membuat alat serta uji coba mesin. Hasil yang diperoleh mesin pemodeling sepatu mampu bekerja secara maksimal 8 jam per hari dengan kecepatan memotong 1,4 menit per pola sepatu, dari hasil tersebut mesin pemodeling mampu memotong desain pola sepasang sepatu dalam kurun waktu 40 menit. Sehingga dalam sehari mampu menghasilkan potongan pola sepatu sebanyak 12 pasang dari yang sebelumnya hanya 2 pasang perhari.
\end{abstract}

Kata kunci: Sepatu bunut, pemotong kulit sepatu, mesin pemodelling digital.

\section{Pendahuluan}

Bunut merupakan salah satu kelurahan di kota Kisaran Kabupatena Asahan yang menyisakan pengrajin sepatu. Nama bunut shoes sudah tidak asing ditelinga penyuka sepatu kulit, yang distribusi produknya menembus pasar nusantara dan mancanegara (Triana, 2018). Sepatu kulit dahulu merupakan produk pabrikan buatan dari Amerika (USA) dan setelah puluhan tahun pabrik ditutup, maka para pengrajin ekskaryawan pabrik sepatu kulit secara turun temurun terus mengembangkan sepatu sehingga kini telah menjadi bagian dari karya industri khas dari kota Asahan (Elfi, 2014). Usaha pengrajin masih terus berjalan, bahkan sudah beberapa generasi. Namun sayangnya, hasil karyanya tidak banyak yang berkembang dalam segi desain model sepatunya sehingga kalah bersaing dengan produk di pasaran (Azhar, 2016).

Hasil wawancara TIM PKM-T dengan pengrajin sepatu di Bunut Kisaran mengatakan bahwa kendala mereka adalah lamanya proses pembuatan sepatu membuat pengrajin sepatu lama dalam proses pemasaran. Begitu juga dalam hal desain model sepatu yang masih menggunakan alat tradisional sehingga model sepatu terkesan ketinggalan zaman. Proses pembuatan sepatu Bunut pada pemotongan kulit sepatu yang masih menggunakan alat tradisional (menggunakan gunting atau dipotong secara manual) membuat proses pemotongan kulit sepatu menjadi lama. Banyaknya permasalahan dalam pembuatan sepatu menyebabkan banyak pengrajin yang meninggalkan usaha sepatu. Permasalahan pengrajin sepaatu membuat TIM PKM-T untuk membantu membuat sebuah alat desain modern di era industri four point zero guna meningkatkan kualitas desain sepatu Bunut sehingga desain sepatu Bunut lebih dapat bersaing dengan desain sepatu lainnya. Dampak yang diharapkan agar omset pengrajin sepatu Bunut di kelurahan Bunut kota Kisaran meningkat (Santoso, 2015).

Solusi tepat guna mengatasi permasalahan pengrajin sepatu adalah dengan membuat alat pemodeling sepatu yang dapat mendesain model sepatu dan memotong kulit sepatu secara praktis dengan menghasilkan model yang lebih menarik, dimana proses ini bekerja dengan memanfaatkan tekanan dari motor penggerak sebesar $210 \mathrm{gf}$ dan keatajaman mata pisau dalam membelah lapisan bahan kulit sepatu setebal 3-5 mm, sehingga dalam proses pemotongan bahan kulit sepatu menjadi lebih cepat dibandingkan dengan menggunakan proses manual (Klein, 2013).

Tujuan dari penelitian ini adalah untuk membantu pengrajin sepatu dalam meningkatkan produktivitas usahanya melalui pembuatan mesin pemodeling sepatu yang berfungsi untuk mendesain dan memotong bahan kulit sepatu sesuai desain pola sepatu yang akan dibuat dengan waktu pendesainan dan pemotongan yang menjadi lebih cepat. 


\section{Bahan dan Metode}

\section{Perancangan alat}

Perancangan pembuatan alat pemodeling sepatu dapat dilihat pada diagram alir yang tertera pada Gambar 1.

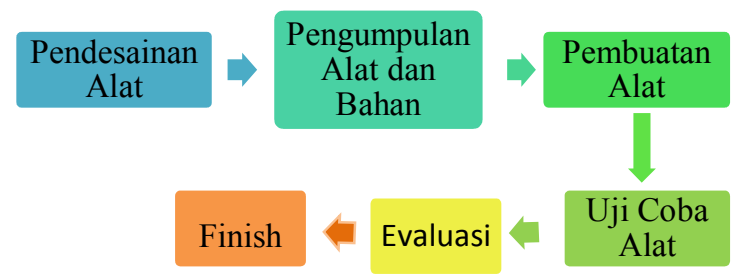

Gambar 1. Diagram alir pembuatan mesin pemodeling sepatu.

a. Desain mesin

Pendesainan mesin dilakukan untuk mempermudah dalam proses pembuatan alat, terutama dalam proses pemilihan dan pengumpulan alat dan bahan. Mesin di desain dengan menggunakan aplikasi Solidworks dengan memperhatikan ketelitian dari panjang setiap komponen yang akan dibuat, ketebalan bahan, serta jenis dan kualitas bahan yang akan digunakan nantinya. Adapun desain mesin seperti tertera pada Gambar 2.

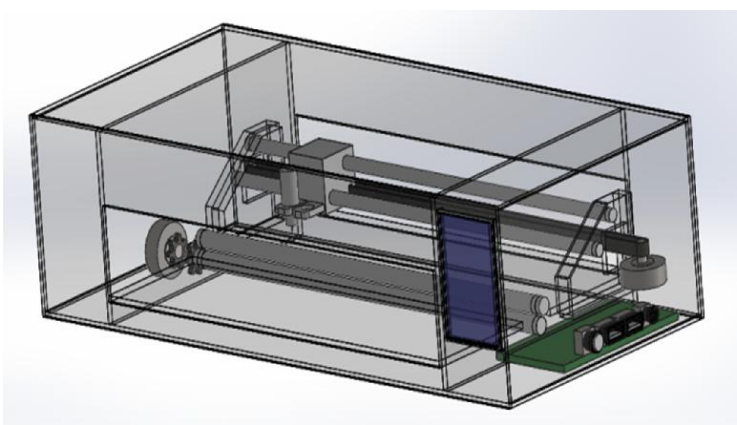

Gambar 2. Desain alat pemodeling sepatu.

b. Alat dan bahan

Alat-alat yang digunakan dalam pembuatan mesin pemodeling sepatu dapat dilihat pada Tabel 1, sedangkan bahan yang diperlukan menurut Tabel 2.
Tabel 1. Alat pembuatan mesin pemodeling sepatu

\begin{tabular}{clc}
\hline No & \multicolumn{1}{c}{ Nama Alat } & Keterangan \\
\hline 1. & Pisau Cutter & 1 Buah \\
2. & Solder & 1 Buah \\
3. & Multi Tester & $1 \mathrm{Buah}$ \\
4. & Obeng & $2 \mathrm{Buah}$ \\
5. & Penggaris & $1 \mathrm{Buah}$ \\
6. & Gunting & $1 \mathrm{Buah}$ \\
\hline
\end{tabular}

Tabel 2. Bahan mesin pemodeling sepatu

\begin{tabular}{clc}
\hline No. & \multicolumn{1}{c}{ Nama Bahan } & Keterangan \\
\hline 1. & Papan Akrilik & 1 Set \\
2. & Lem Akrilik & 1 Botol \\
3. & Adaptor & 1 Buah \\
4. & USB Cable & 1 Buah \\
5. & Dinamo Stapper & 2 Buah \\
6. & Mother Board & 1 Set \\
7. & Layar LCD & 1 Buah \\
8. & Rotor & 1 Set \\
9. & AS Rotor & 2 Buah \\
10. & AS Penggerak & 2 Buah \\
11. & Belt & 1 Buah \\
12. & Timah Solder & 1 Buah \\
13. & Selotip & 1 Buah \\
\hline
\end{tabular}

c. Pembuatan alat

Proses pembuatan alat pemodeling sepatu dilakukan di rumah salah satu tim PKM-T dengan skema terlihat seperti pada Gambar 3. 


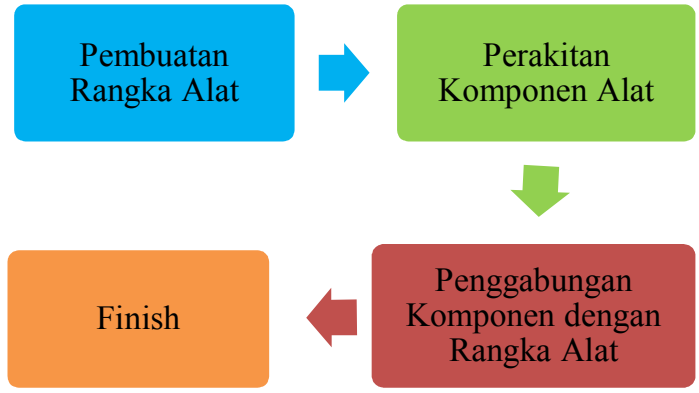

Gambar 3. Proses pembuatan alat pemodeling sepatu.

\section{d. Uji coba mesin}

Uji coba dilakukan untuk mengetahui kinerja dan kemampuan mesin apakah dapat beroperasi seperti yang diharapkan. Uji coba dilakukan ketika alat sudah selesai di buat dan pelaksanaan uji coba dilaksanakan di tempat mitra yang berada di kelurahan Bunut kota Kisaran.

\section{e. Evaluasi}

Evaluasi dilakukan setelah pelaksanaan uji coba alat, dimana dari uji coba didapat hasil berupa kelemahan dan kekurangan mesin saat bekerja, dari hasil temuan ini TIM PKM-T melakukan evaluasi guna penyempurnaan alat pemodeling sepatu.

\section{Proses Pembuatan Mesin}

Pembuatan mesin pemodeling sepatu dimulai dengan mengumpulkan semua alat dan bahan seperti terlihat pada Gambar 4a dan 4b.

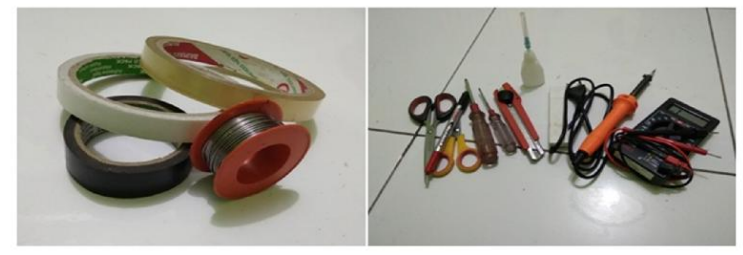

Gambar 4a. Alat yang digunakan untuk membuat alat pemodeling sepatu.

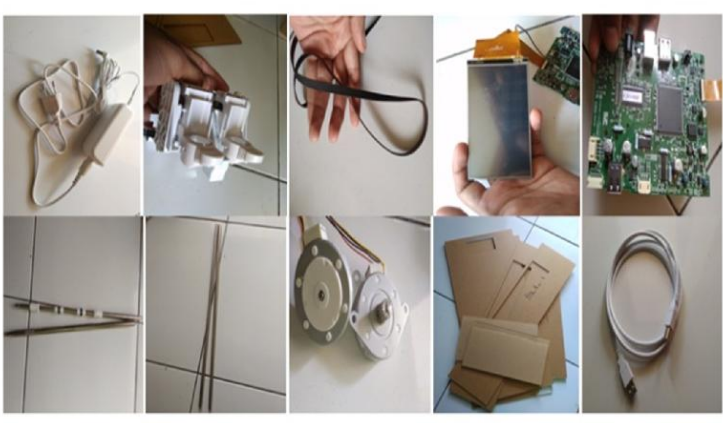

Gambar 4b. Bahan yang digunakan untuk membuat alat pemodeling sepatu.

Setelah semua alat dan bahan terkumpul, maka proses pembuatan mesin dilakukan dengan langkah pertama yaitu membuat rangka mesin yang terbuat dari papan akrilik setebal $3 \mathrm{~mm}$, papan tersebut dipotong dengan menggunakan mesin gerinda berkecepatan 1500-3000 rpm dengan menggunakan mata gerinda berdiameter $100 \mathrm{~mm}$ setebal $3 \mathrm{~mm}$, proses ini dapat dilihat pada Gambar 5.

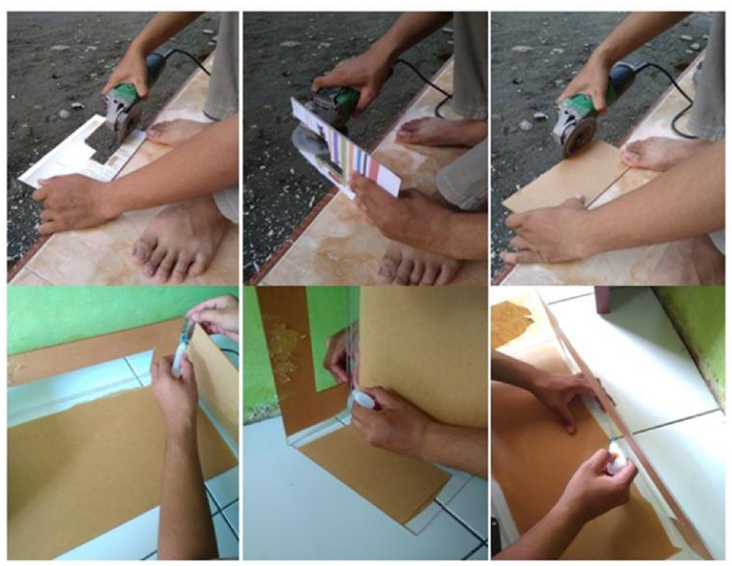

Gambar 5. Pembuatan rangka alat.

Langkah selanjutnya yaitu merakit komponen-komponen alat seperti terlihat pada Gambar 6. 


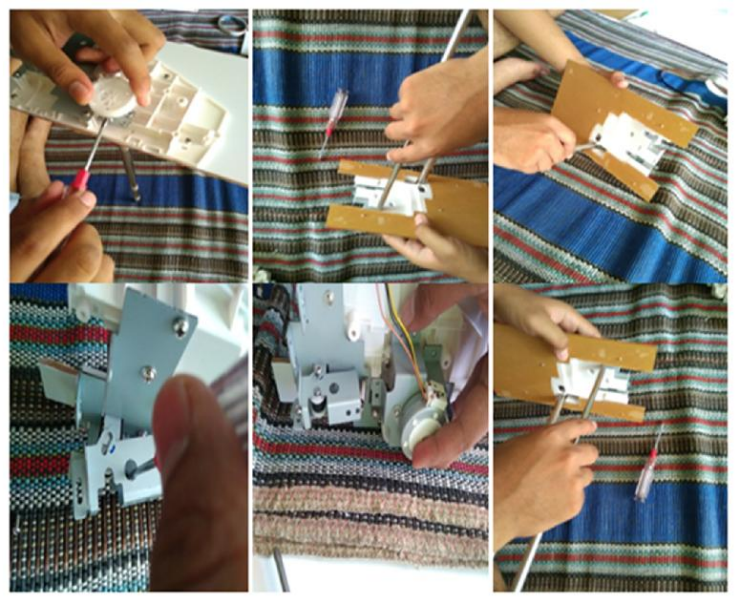

Gambar 6. Perakitan komponen mesin.

Setelah rangka dan komponen selesai di rakit, maka langkah terakhir yaitu menggabungkan kedua bagian menjadi satu, dengan mendudukan komponen-komponen mesin ke dalam rangka mesin. Hal ini dapat dilihat pada Gambar 7.

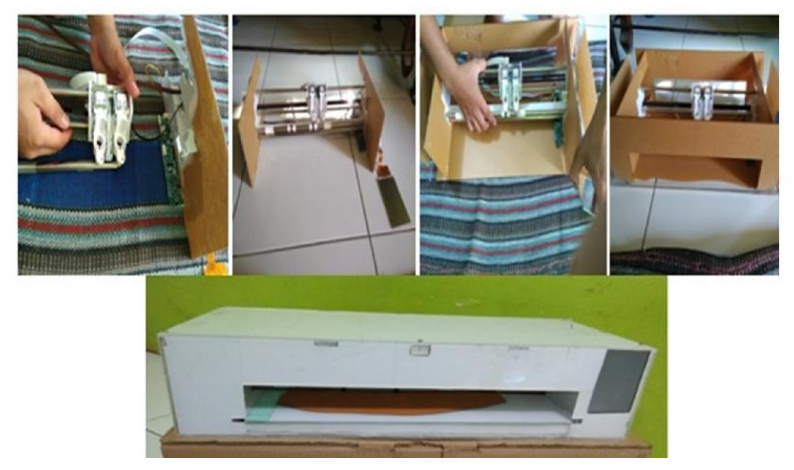

Gambar 7. Penyatuan rangka alat dengan komponen alat.

\section{Cara Kerja Mesin}

Cara kerja mesin pemodeling sepatu terbagai atas 3 proses sebagaimana ditunjukkan pada Gambar 8 .

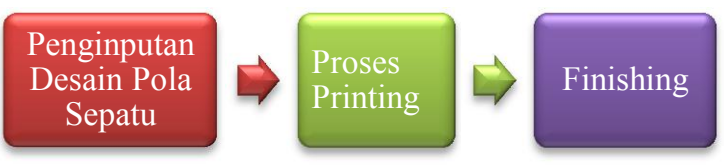

Gambar 8. Proses kerja alat pemodeling sepatu. a. Penginputan desain pola sepatu

Penginputan desain pola sepatu merupakan proses pentransferan file desain dari aplikasi gambar desain seperti photoshop, corel draw, dan program lain ke aplikasi alat pemodeling sepatu, setelah file ditransfer, maka alat pemodeling sepatu dapat memproses desain pola sepatu (Anonymous, 2016).

\section{b. Proses printing}

Proses printing merupakan proses pemotongan bahan kulit sepatu sesuai dengan desain pola sepatu yang sebelumnya sudah diinput ke aplikasi alat pemodeling sepatu (Berman, 2012).

\section{c. Finishing}

Finishing merupakan proses terakhir dalam pemotongan bahan kulit sepatu, dimana bahan kulit sepatu yang tadinya dimasukkan ke dalam alat pemodeling sepatu setelah selesai di potong kemudian dikeluarkan agar dapat diambil dan digabungkan menjadi satu kesatuan sebuah sepatu Bunut.

\section{Hasil dan Pembahasan}

Hasil yang diperoleh dari pengujian mesin pemodeling sepatu yaitu mesin pemodeling sepatu mampu memotong 1 desain pola sepatu dengan tekanan mata pisau sebesar 40 gf dengan waktu 1,4 menit, sementara untuk menghasilkan satu buah sepatu terdiri dari 7 desain pola sepatu dengan waktu potong 9.8 menit. Jadi untuk menghasilkan sepasang sepatu mesin mampu memotongnya dengan waktu 19.6 menit. Hasil ini dapat berubah sesuai dengan jumlah desain pola sepatu, karena setiap jenis sepatu berbeda pula jumlah desain pola sepatunya. Produksi sepatu yang di hasilkan dari mesin dapat dilihat pada Tabel 3.

Hasil pengujian mesin menunjukkan hal yang positif bagi mitra, karena dapat meningkatkan produksi desain pola sepatu Bunut. Hal ini dilihat dari hasil produksi desain pola sepatu Bunut mitra yang hanya 2 pasang sepatu perharinya dengan memakai metode konvensional. Sementara jika memakai mesin pemodeling dan pemotong kulit sepatu di 
perkirakan dapat memangkas waktu pemodelingan desain pola sepatu sehingga proses produksi desain pola sepatu dapat meningkat (Spahiu, 2016). Hal ini dapat dilihat dengan menghitung jumlah waktu yang ditempuh mesin ini saat bekerja dengan kerja maksimal yaitu 8 jam per hari, jika model sepatu yang diinginkan berjumlah 7 desain pola sepatu.

Tabel 3. Produksi sepasang sepatu bunut.

\begin{tabular}{ccc}
\hline No & $\begin{array}{c}\text { Jumlah Desain } \\
\text { Pola Sepatu }\end{array}$ & $\begin{array}{c}\text { Waktu Pemotongan } \\
\text { (menit) }\end{array}$ \\
\hline 1. & 5 & 14 \\
2. & 6 & 16.8 \\
3. & 7 & 19.6 \\
4. & 8 & 22.4 \\
5. & 9 & 25.2 \\
\hline
\end{tabular}

Maka waktu yang diperlukan untuk memotong pola sepatu yaitu 19.6 - 20 menit, jadi dalam sehari 8 jam kerja mesin ini mampu memotong desain pola sepatu sebanyak 12 pasang sepatu atau 6 kali lipat lebih cepat dibandingkan menggunakan metode konvensional (memotong secara manual dengan menggunakan gunting).

\section{Kesimpulan dan Saran}

Mesin pemodeling sepatu bekerja menghasilkan 12 potong desain pola sepatu dalam satu hari (8 jam kerja), mata pisau mesin pemodeling sepatu akan dibuat lebih tajam sehingga dapat bekerja semakin efektif, sehingga mampu memotong dengan bahan kulit yang bervariasi mulai dari ketebalan $3 \mathrm{~mm}$ sampai 5 $\mathrm{mm}$.

\section{Ucapan Terima Kasih}

TIM mengucapkan terimakasih kepada RISTEKDIKTI yang mendanai kegiatan PKM$\mathrm{T}$, Rektor Universitas Negeri Medan dan jajarannya, Mitra sepatu Bunut, kepala bengkel Fakultas Teknik Universitas, serta kepada ibu Dosen Pendamping yang telah membimbing terlaksananya kegiatan, dan buat semua pihak yang telah mendukung.

\section{Daftar Pustaka}

Anonymous, 2016. Articels: What is the Best Type of Plastic for my 3D Printing Application? Diakses 9 November 2018, dari 3D matter, Unlocking Properties.http://my3dmatter.com/ whatis-the-best-type-of-plastic-for-my-3dprinting-application/

Azhar, Z., 2016. Pemasaran Sepatu Bunut Kisaran Menggunakan Konsep ECommerce. Jurnal Teknologi dan Sistem Informasi, 3(1):1-13.

Berman, B., 2012. 3D Printing: The New Industrial Revolution. Bussines Horizon, 55(2): 155-162.

Elfi, J., 2014. Mobilitas Sosial dan Keberdayaan Ekonomi Keluarga Pengrajin Sepatu di Bunut Kecamatan Kisaran Barat Kabupaten Asahan. Skripsi, Fakultas Sosial dan Ilmu Politik Universitas Sumatera Utara, Medan.

Santoso, 2015. E-Marketing pada UKM Sepatu Bunut Abang Adik Kisaran, Jurnal Teknologi Dan Sistem Informasi. 1(2):8795.

Spahiu, T., 2016. 3d Printing As A New Technology For Apparel Designing And Manufacturing. International Textile Conference.

Triana, M., 2018. Analisis Faktor Produksi Industri Kecil Sepatu Bunut di Kabupaten Asahan (Studi Kasus Bunut). Skripsi, Fakultas Ekonomi dan Bisnis Universitas Sumatera Utara, Medan.

Klein, G., 2013. 3D Printing and Neurosurgery Ready for Prime Time? World Neursurgery. 80(3) :233-235. 